\title{
Performative Archaeology: Exploring the use of Drama in Archaeology Teaching and Practice
}

\author{
Konstantinos Prokopios Trimmis and Konstantina Kalogirou
}

\begin{abstract}
This paper aims to explore the possible applications of drama and performance as research and teaching 'tools' in archaeological practice. A brief presentation about previous attempts to apply drama and performance in archaeology will be followed by a detailed analysis of how drama can be beneficial in the context of Archaeological teaching and practice. The theoretical discussion is later organized around a methodological framework. The discussion is supported by a presentation of the pilot application of the proposed methodology in Santorini island's archaeological caves, and a brief summary of the application's outcomes.
\end{abstract}

All arts add

to the richest of the arts,

the art of life.

(Bertolt Brecht)

\section{Archaeology as Performance}

The performative idea is not something entirely new in the scholarly debate in Archaeology. Since the late 80s/early 90s there has been a focus on the perception of socially 'performed roles' (e.g Tringham 1991, Hodder 2006) and the performative construction of gender (for a thorough discussion see Butler 1990, and Parker and Kosofsky Sedgwick 1995; for reference to gender in the archaeological context see Tringham 1991). Furthermore, the work of Victor Turner (1988) and Richard Schechner (1985) is noteworthy in this context. They observed and discussed the performative nature of societies around the world, how events and rituals as well as daily life were all governed by a code of performance and argued that performances are central to human understanding. In opposition to these views on the study of performance in archaeology, Peggy Phelan suggests that a "performance's only life is in the present"; and further argues that it "cannot be saved, recorded, documented, or 
otherwise participate in the circulation of representations of representations: once it does so it becomes something other than performance" (1993:146).

This paper aims to explore the performativity of the archaeological self; to identify if the performativity of archaeology as a process, as will be explored later, can be used to establish a greater understanding of the past and the creation of archaeological narratives, complementary to the other established research tools, such as creative writing and storytelling (see Skeates 2015). In other words, can theories of performativity - and their adaptations to archaeology - move from their already existing nature, the traditional implementation as interpretational tools, to applications of performance as research methodology?

Applications of performance as a method to enhance traditional research methodologies have been applied in several research fields with encouraging outcomes (for a review see Lewis and Tulk 2016). While we have been amazed by the example of applying drama as a research tool for better understanding star deaths in the field of Astronomy (see Cervera 2017), the performing arts have been similarly applied in Sociology, Mathematics, Physics, History, and Economics, to name just a few, and of course, Archaeology. Application of performance in archaeological research as a research tool has been discussed in Parker and Shanks' book which explores the relationship between Theatre and Archaeology (Pearson and Shanks 2001). Recently, performative applications, more Theatre than Drama oriented, have been used for the interpretation of the Minoan House space (Performance - Archaeology n.d. - see Fig. 1) for the understanding of Neolithic migration/feasting in Koutroulou Magoula in Thessaly, Greece (Performance - Archaeology n.d.) and for the interpretation of Dogu culture figurines (Takahashi 2016). Unfortunately, most of these applications have not published their outcomes yet. The only available evidence are the videos from the relative performances that can be found online. This paper aims to initiate a debate on the possibility of a performative turn in archaeological research, or simpler yet, if it is possible for performance and drama to be used as tools by archaeologists to interpret and understand past societies.

Even if 'performativity' as a term has been used and exploited in different disciplines and in a variety of contexts within each discipline, in Theatre and Anthropology it generally introduces the idea that everyday life is an interaction of individuals who perform roles (Parker and Kosofsky Sedgwick 1995:2). As Turner writes the "basic stuff of social life is performance, the presentation of self in everyday life. Self is presented through the performance of roles, through performance that break roles and through declaring to a given public that one has undergone a transformation of state and status, been saved on demand elevated or released" (1988: 80). Projecting this to archaeological practice, as noted in the online space of Joukowsky Institute for Archaeology and the Ancient World at Brown University, where a course on Archaeology as Performance has been taught, "Archaeology has been and continues to be performed by archaeologists, who are themselves 'turned' into archaeologists by 'performing archaeology' - this is a mutually constitutive relationship. It 


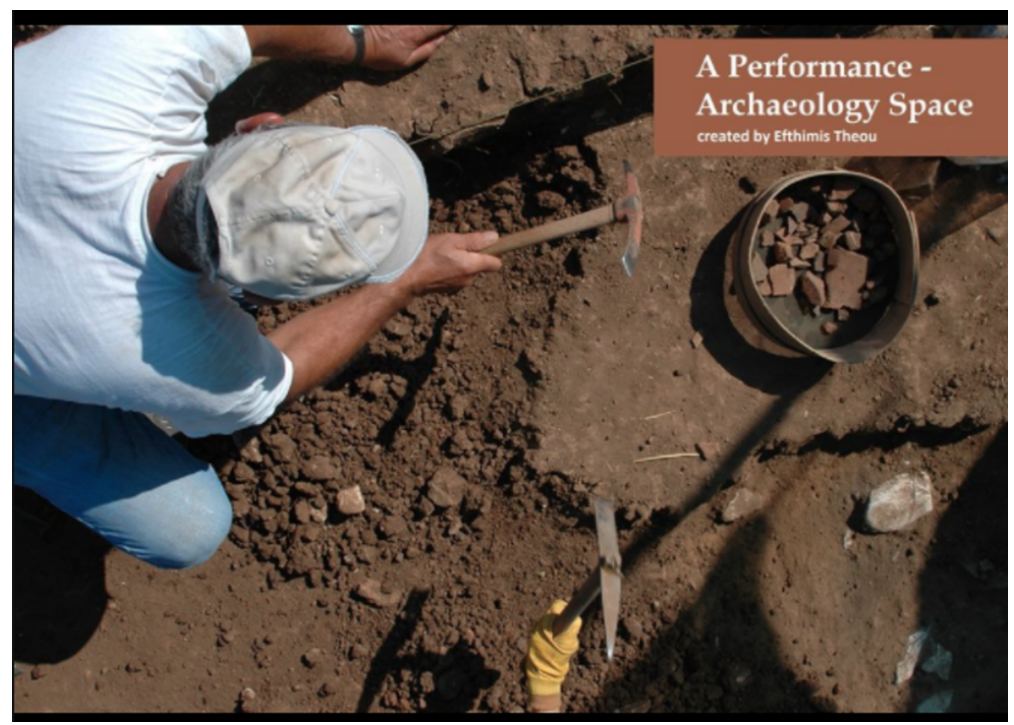

Figure 1: The Performance-Archaeology online space, which has been created by Efthimis Theou. E. Theou facilitated the Gavdos House performance and participated in the Koutroulou Magoula performance experiment (Courtesy of E. Theou)

is in these actions, or 'performance(s)' that archaeology actually exists..." (Joukowsky n.d. )

Therefore, and moving from performance to applied drama, organized/facilitated performative applications, such as modern dance in a ceremonial cave chamber, can be deployed in order to understand different contexts better; thus, applications of drama have been introduced in education, social studies, social care, psychology and linguistics. Our goal is to examine if drama can be applied to gain an alternative understanding of the archaeological context. We have chosen drama from the rest of the performative arts palette because with drama, participants develop intellectual, social, physical, emotional and moral domains and engage themselves with each other's thoughts, feelings, bodies and actions (Kalogirou 2016). Mainly, and we will see how this is related to a performative archaeology approach later, drama a) challenges participants to make meaning of their world, and to experience, feel and interpret it; b) empowers participants to understand and influence their world through exploring roles, objects and situations; c) allows participants to explore, shape and symbolically present ideas and feelings and their consequences. Also, drama moves and challenges values, memory, cultures and identities (Kalogirou 2016).

\section{The Third Paradigm}

The arts, in general, are defined as a field which stimulate sensory and perceptual activity and develop mind and body (Ehrenspeck 1998). Performance in particular is a bodily practice that produces meaning. It is the presentation or 
're-actualization' of symbolic systems through living bodies as well as lifeless mediating objects (Seitz 2016); in our case, the researcher and the research activity are the living bodies and the research data is the lifeless mediating object. When it comes to archaeological research, the data handled by the researcher is fragmented, and a portion of it is lost in time. Thus, it is unlikely for this original data to be put into the words of a report or a publication, even if they are often fully incorporated into the rational horizon of the researcher's understanding. As Hamilakis notes in the introduction of the Archaeology of Senses, a researcher's background might change the interpretation of the same data. For this reason, he proceeds to offer a detailed presentation of his background as an author (Hamilakis 2013). In the same vein as Hamilakis, Holly Moyes, in the introduction to Sacred Darkness, notes that the dichotomy between sacred and profane, which her work encapsulates, might be a modern perception that is reflected in the research outcomes (Moyes 2012). Ultimately, Hodder and other post-processualists acknowledge the incorporation of contemporary ideas in the interpretation of the past as an unpreventable effect (for a brief discussion see Hodder 2005). In our approach we would like to turn the tables and have people's active perceptions - cultivated through drama - to function complementary to the 'hard' data and not as an unpreventable research limitation.

The use of performance to understand a concept, a space or a meaning, might sound like a relatively new idea, a product of post-modern approaches that have been blossoming since the 70's. However, according to Pettit, Palaeolithic cave art and shamanism can be understood as a primitive performative way that Palaeolithic societies utilized to understand their world (Pettit 2016). From a contemporary perspective, in 2008 the online journal Forum: Qualitative Social Research (FQS) published a special issue on Performative Social Science research with more than forty contributions devoted to arts-based practice (see Seitz 2016 for a summary). There are also several other authors who explore the applications of the performative arts as a research tool (e.g. Borgdorff 2007; Seitz 2009, 2016; Troendle and Warmers 2011). Here we need to note Borgdorff and Seitz's own hesitation to incorporate artistic research into the recognised 'fields of Science and Technology' as they are presented in the 'Frascati Manual', even if both support the idea that artistic research is 'research indeed' that produces actual and tangible outcomes that can be complementary to other, established, empirical research (for detailed discussion see Borgdorff 2009; Seitz 2016: 304- 306).

The overall idea might seem controversial for an empirical researcher who aims to create data in order to answer set questions and to examine the validity of well-defined theories. Performative research has been described, however, as "the third research paradigm" - with quantitative and qualitative research being the other two - because it aims not to answer any existing questions, to test hypothesis or to document processes; but rather it aspires to be one with research practice and to generate new insights through 'being' research instead of 'doing research' (Seitz 2016). 


\section{Performative Research (PR) and the Process Drama (PD) approach}

If everyday actions are performed, therefore research actions are performed. In other words, a researcher analysing an artefact or a space using traditional disciplinary approaches performs actions/roles, which might be contradictory or complementary to other roles that this individual may undertake in their everyday life. The facilitating role that this individual will undertake in a Performative Archaeology approach would complement the performance that they are already part of (see Fig. 2). The overall idea can be structured around a performative experiment that will use Process Drama tools in a pre-arranged specified timescale.

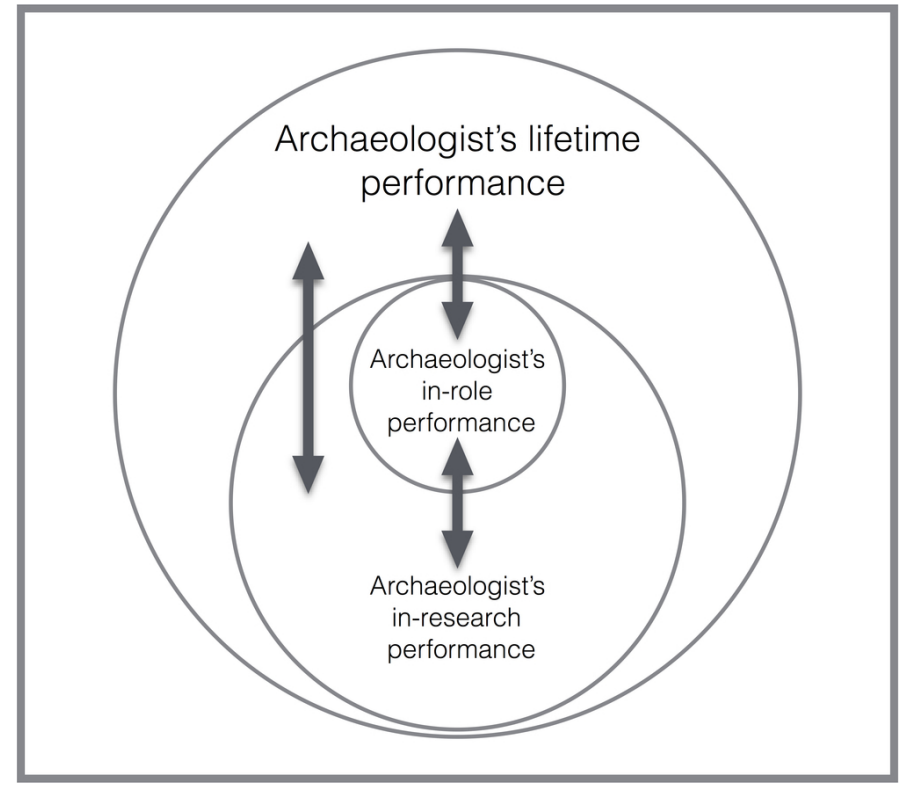

Figure 2: Venn diagram showing individual's work performance in the lifetime performances (based on Prof. Wolfgang Hallet's idea modified by the authors)

Research itself is a multidimensional process and it can be radically altered by any number of possible ethnic, religious, cultural or terminology boundaries that might arise among diverse colleagues, researchers or students (Ronen 2001). This can be tackled if research is approached and conducted through universal tools and mediums that cannot be easily misinterpreted, such as drama. In general, drama, according to Slade, is the 'Art of Living', it is "an art form in its own right which should be recognized, respected, nurtured and developed" (Bolton 1999: 9). Also, Day and Norman suggest, that drama is a suitable medium to cultivate cognitive skills and an adaptable tool (Day \& Norman 1983: 29). Wagner also explained that "drama is a technique that can be employed to cope with new or unsettling experience" (Wagner 1976: 16). Drama also encapsulates broad creativity and imagination and as a result it becomes an effective tool for diverse, multicultural, multi-ethnic, multireligious classes with 
different understandings of the target terms, such as archaeology, past, history and others, because it integrates, engages and encourages participation while it also offers the participants anonymity, playfulness and freedom (Kalogirou 2018). We propose Process Drama, from the different genres of drama, as the most suitable to be used as a medium for performative archaeology. We positively support, however, that other drama and performance applications could be also adopted. Process Drama allows and encourages the facilitator and the participants to work together, aiming to create an imaginary setting so as to explore a particular situation, solve an issue, deal with a theme (or series of related themes). Ultimately, Process drama (PD) is not intended for an audience but for the benefit of the participants themselves (Bowel and Heap 2013). Process drama is both social and individual. First, it requires the active participation of others, it involves negotiation and renegotiation of the interpreted meaning and, second, it is done for the benefit of the participants themselves and not for a separate audience (Bowell \& Heap 2013). A few of the Process Drama tools that we incorporate into the Performative Archaeology approach, such as Hot-seating, Mantle of the Expert, Interview, Speaking Objects, Still Image (Tableau), are to an extent already in use in archaeological research. For example, the 'Dogu-mime' experiment is based on the use of the Still Image (tableau) tool in combination with mime and physical theatre techniques. Dogu are clay figurines from the Jomon period (ca.16000-2400 calBP), which exaggerate the human image. "The performance of 'Dogu-mime' is an attempt to visualize the ideas of the Jomon people, who made the Dogu figurines..." (Takahashi 2016:82). The performer is not only an archaeologist but also a mime (with the stage name Hakucho-kyodai), who has been performing this Dogu-mime on streets, stages, and museums in Japan, since 2010 (Takahashi 2016) (Fig. 3). However, other PD tools such as, Archaeologists in Role, Decision Alley, Data Improvisation, Forum Theatre, Role-On-The-Wall, have never been proposed or tried before in archaeological practice, even if archaeologists are, in a way, already using similar techniques for group collaboration and data interpretation (the listing of Drama tools is based on Baldwin and Hendy 1994).

As an example, Role-On-The-Wall (Bowel and Heap 2013) encourages participants to brainstorm on a given topic and write their ideas on a 'wall'/paper. Afterwards participants can discuss these ideas or create physical performances based on the 'scenario' that has been 'created' by the team on the wall. Forum Theater (Boal 1995) can be used for problem-solving since it is created by a group that performs a topic which has been set by a Joker and builds the problematic around the topic. The Joker then asks the audience to propose a solution and to step up and perform the idea working collaboratively with the initial performing group.

All these techniques can be used individually or as complements to each other, in any possible format and alongside well-established empirical methods. However, we suggest that for better and more robust results, for getting the most out of the Performative Archaeology approach, these tools need to be used 


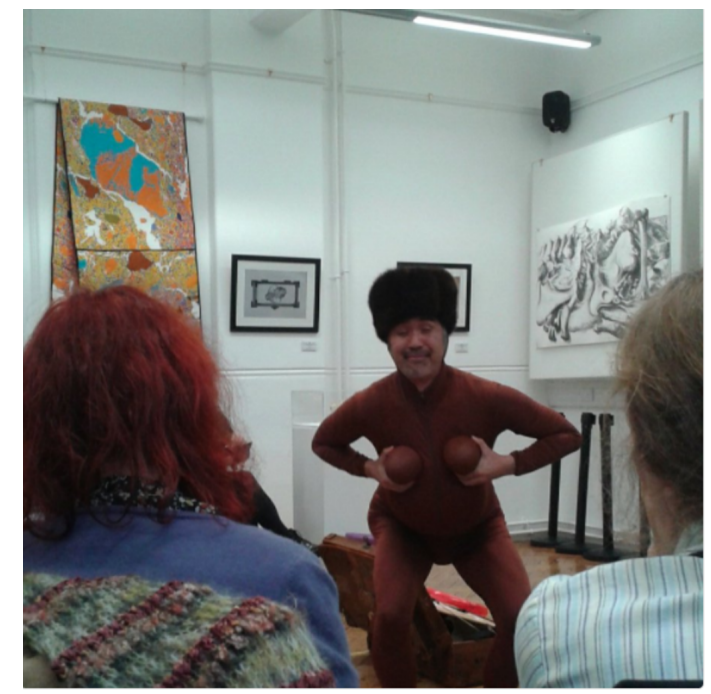

Figure 3: K. Takahashi performs Dogu-mime at Theory Archaeology Group conference in Southampton 2016 (Courtesy of @SERFProject)

in a context of time-framed research workshops, where the participants will first build a drama group, then run the experimental exercises, deal with the set topic in a team/task-based activity, which will deliver the tangible outcomes; or in a more traditional way, the quantitative/qualitative data can also be used as research outcomes.

Authors have named the structured way of dealing with a research topic through drama applications, as the $3 \mathrm{E}$ method. $3 \mathrm{E}$ is an application for interpreting, exploring and re-constructing participants' own narratives about a target object or notion. Its principles are derived from Process Drama (PD) and Task Based Learning (TBL) (Kalogirou et al 2016).

Exposition: warm up activities for introducing the target, key words, and key definitions. For this stage icebreakers can be used along standard Drama games such as 'Two Lies and a Truth', 'Find Your Shield - Avoid Your Enemy', and 'Opinion lines' in order to introduce the topic, foster teamwork and create a co-working atmosphere.

Exploration: Drama, Music and Design activities to explore and experience the target. The standard Process Drama tools can be used here as the core activities of the workshop.

Exhibition: a team-based task within a context, with tangible deliverables to recycle the target ideas and acquire them. The Exhibition element can vary from a performance - as the Performance-Archaeology group supports to a general research report which showcases and presents the performative archaeology outcomes. This is done through the application of creative writing and storytelling - as will be presented in this paper's case study.

As noted before, Performative Archaeology is not aiming to create a theatrical performance based on archaeological data, as is the case with most of the current experiments. Rather, it aims to use performance - and drama to 
analyse, interpret and understand the data in the manner of a 'Third Research Paradigm'. These activities can be adapted and applied to the research environment/archaeological context without requiring special equipment, though specific drama trained participants are required.

\section{Towards an understanding of the past}

As performance and drama are applied today for a better understanding of the self in different socially constructed spaces (Drama/Theatre in Education, Prisons, Hospitals) we are equally positive that drama can be adapted to the archaeological context, not only as a tool for communicating narratives about the past in educational contexts (Kalogirou et al 2016) but also as a complementary tool to construct those narratives. As we noted before, the overall idea is to embody research and, through constructed, drama-based activities instead of an interpretation of the empirical data, to proceed to an "embodied understanding of the information". The main scope for a Performative Archaeology approach, from our perspective, is to modify the drama principles that have been presented before to a) challenge participants to make meaning of past worlds, experience, feel and interpret them; b) empower participants to understand and influence the past worlds through exploring roles, objects and situations; c) allow participants to explore, shape and present ideas and feelings and their consequences.

\section{The Santorini experiment}

In order to challenge these principles, we organized an experiment during the Cardiff University archaeology fieldwork season on Santorini island in Greece, in the summer of 2007. Konstantinos Trimmis (KPT) wes leading a cave archaeology project, which aimed to explore, record, and archaeologically investigate the island's natural caves, under the general project of Dr F. Mavridis and the Greek Ephorate of Speleology and Paleoanthropology that aims to record the archaeological caves of Cyclades island complex. Santorini is a volcanic island in the southern Aegean and is famous for its breath-taking views over its volcanic caldera and the Akrotiri prehistoric town that was buried under volcanic material in the middle of the $16^{\text {th }}$ century BC (for more about Akrotiri see Doumas 1983).

The Santorini team in summer 2017 consisted of nine members; Konstantina Kalogirou (KK) took the initiative to organize a five day 'Performative Archaeology' workshop at the end of the fieldwork so as to evaluate if drama could help team members to 'understand' the collected data in a different (or even, better) way. The workshop was organized with two objectives, along with the assumptions that we presented earlier in this paper:

- Building teamwork and communication: to strengthen the team spirit between participants, allowing them to trust each other through process 
drama creative activities and encouraging them to share their views, combine their opinions and get inspired from each other's perspectives.

- Understanding the archaeological evidence: to offer an alternative way of researching, interpreting, and correlating the data. Also, as we have students as participants, the workshop aimed to challenge and improve the participants' academic writing skills to help them deliver a better fieldwork report by exposing them to the beneficial effects of process drama and task-based learning on the subject of writing.

The 'Performative Archaeology' workshop took place over the last five days of the 21 in total that the fieldwork lasted. The reason why the drama workshop took place over the last five days was to allow participants to gain as much impetus, data, information and experience from the place and space, time, working conditions and fieldwork concept, as possible.

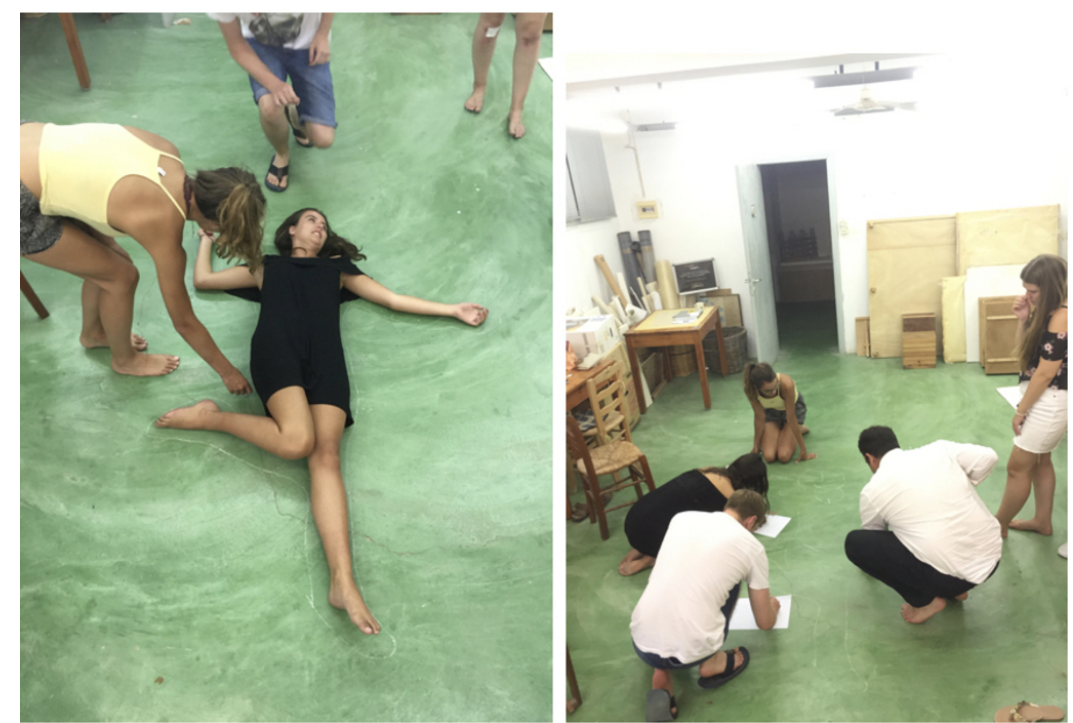

Figure 4: Performing Artefact on the floor in Santorini, summer 2017 (Courtesy of K. Kalogirou)

On Santorini the project was run in 5 parts/workshops. Each workshop lasted between $1 \mathrm{~h}$ and $1 \mathrm{~h} \mathrm{45}$. The first four workshops took place in a suitable vacant room at the Akrotiri excavation premises, while the last one took place in the surrounding area, so participants could re-engage with the external space in a different way. All the workshops had been video recorded for evaluation and training purposes. All the activities had been facilitated by KK, while KPT participated in the workshop in order to motivate, inspire and engage the participants (see also Table 1). The data that we aimed to explore through drama was the quantifications of the surface pottery in the target caves, the cave surveys, the standing structures that have been recorded inside the caves, along with photos, 3D photogrammetrical-produced imagery from features, oral history recordings, ethnographic data and literature review 
information. There were some activities, mainly for the Exposition part, that were implemented without requiring any adaptation from a drama exercise to an archaeology research tool such as: Untangle, Mirror your Partner, Bomb and Shield. Some other activities for the Exploration part though, required an adaptation to an archaeological context; such as: Charades your archaeology (charades), Artefact on the wall (Roll On the Wall) (Fig. 4) or Indiana Jones' footsteps (Grandma's footsteps). There were also some activities, again for the Exploration part, that were designed exclusively for this project such as: 'Alphabetize my Archaeology', 'Archaeological Actions', 'Who? Where? What?'. As far as the final part of all the workshops is concerned, namely the Exhibition part, the participants had to discover key information through research and observation, brainstorming, begin paragraphs, draft and finally produce a love letter to a fellow archaeologist with whom they were separated by a great distance but deeply in love with and needed to share their own personal experience of spending time in a new archaeological field. The reason a written task was chosen as a deliverable is because we aimed to provide participants with a chance of writing practice that would include general information, data, personal experiences, subjective views and objective facts that altogether would be used to produce a romantic and fun concept, such as that of a love letter. In this way it was easier for the piece of work to be produced compared to a 'dry' field report, but at the same time it was an actual field report that could be easily re-written in formal/technical language.

In order to evaluate the participants' experience from the workshops and if a performative approach in archaeological research helps towards a better understanding of archaeological evidence - and to an extent a better understanding of the past - we distributed a survey/questionnaire. In the first question, if the content of the workshop was interesting, one of the five participants agreed strongly (5/5), three of them agreed (4/5) and one of them found it average (3/5). In the second question, if they enjoyed participating, two of them agreed strongly (5/5), two of them agreed (4/5) and one found it average $(3 / 5)$. On the third question, four of them strongly agreed $(5 / 5)$ that the workshop environment was comfortable and safe, while one of them agreed $(4 / 5)$. On the fourth question, three of them strongly agreed $(5 / 5)$ that they grew in their abilities to focus and work creatively within a group, one agreed $(4 / 5)$ and one found it average (3/5). On the penultimate question, enquiring if the difficulty of the workshop was appropriate, two of the participants strongly agreed (5/5), two agreed (4/5) and one found it average (3/5). In the last question, if the workshop helped them to understand the available archaeological data, four strongly agreed (5/5) and one found it average (3/5). Based on the anecdotal feedback, one participant claimed that "one of the greatest strengths of the workshop was the new, interesting way to look at and interpret data", while a second participant claimed that the workshops made it easier to "hear everyone else's opinions on certain matters". A third claimed that drama offered them a relaxing and liberated way to process archaeological evidence. Finally, a fourth participant noted that the drama games and activities 
Table 1: An outline of the Santorini workshops with a brief presentation of the drama exercises

\begin{tabular}{|c|}
\hline Santorini Drama Workshop: $20^{\text {th }}$ July $2017-25^{\text {th }}$ July 2017 \\
\hline Exposition: warm up, ice breaking, team building \\
\hline $\begin{array}{l}\text { - Pass the palm: feel the team, listen beyond hearing } \\
\text { - Mirror your peer: learn to lead, follow and respect (Fig. 5d) } \\
\text { - Untangle: touch, play, look after each other (Fig. 5b) } \\
\text { - Trust me with your fall: trust, support, believe, respect } \\
\text { - Bomb and shield: trust, support, make fun } \\
\text { - Invite me and you die: trust, invite, welcome, be quick } \\
\text { - Hands of power: trust, respect, listen, lead and follow } \\
\text { - Don't need to see: learn to use the rest of the senses beyond seeing, trust and look after each } \\
\text { - } \text { other } \\
\text { - } \text { Be the artefact: pretend, learn, explore, think, improvise, understand the team } \\
\text { - Indiana Jones' footsteps: all-time classic counting and waiting game } \\
\text { - Find the leader: learn the team, identify patterns and preferences }\end{array}$ \\
\hline Exploration: Experiential and Performative Exploration of Archaeological Evidence \\
\hline $\begin{array}{l}\text { - Alphabetize my archaeology: name all the relevant archaeological words you encounter in the } \\
\text { project } \\
\text { - Archaeological actions: perform an archaeological action and let the team name it } \\
\text { - } 10 \text { " object: perform an object from the project and let the team name it } \\
\text { - Share the truth about... being an archaeologist: perform personal views in an action } \\
\text { - } 2 \text { truths and } 1 \text { lie about Santorini caves: share true and false information about the project and } \\
\text { let the team find the odd one out } \\
\text { - } 1 \text { word at a time: perform and build up a story inspired by the project using a single word per } \\
\text { person } \\
\text { - Improvisation: Who? Where? What?: participants in pairs are asked to perform the information } \\
\text { given on a piece of paper, namely } 3 \text { key words (a person, a place and an action) and the rest of } \\
\text { the team has to guess Who? Where? Doing what? (Fig. } 5 \text { a and } 5 c \text { c) } \\
\text { - Artefact on the wall: a participant performs with their body an artefact and the rest of the team } \\
\text { shape it, in real dimensions, on a piece of A0 paper on the floor, where all the team writes down } \\
\text { all the data and facts they know/can recognize. Collective and previous knowledge is activated } \\
\text { (Fig. } 4 \text { ) } \\
\text { - Pick and continue: Beginnings of sentences, relevant to the project, are written on a piece of } \\
\text { paper. Participants are asked to continue the sentences in order to perform a coherent story as a } \\
\text { team } \\
\text { - Hot Seat: One participant is an important object/artefact/place related to the project and the rest } \\
\text { of the team ask questions seeking to find out what the performer is. }\end{array}$ \\
\hline Exhibition: Writing the project report in the form of a love letter to a fellow archaeologist \\
\hline $\begin{array}{l}\text { - Phase A: plan the love letter, think of key words, brainstorm the main problem } \\
\text { - Phase B: write in paragraphs, connect the facts with the love story } \\
\text { - Phase C: write in the form of a love letter, enrich the story with incidents and characters } \\
\text { - Phase D: Finish the love letter and share it with the group }\end{array}$ \\
\hline
\end{tabular}


they had been through offered them new and unexplored perspectives on how to interpret archaeological data and finds.

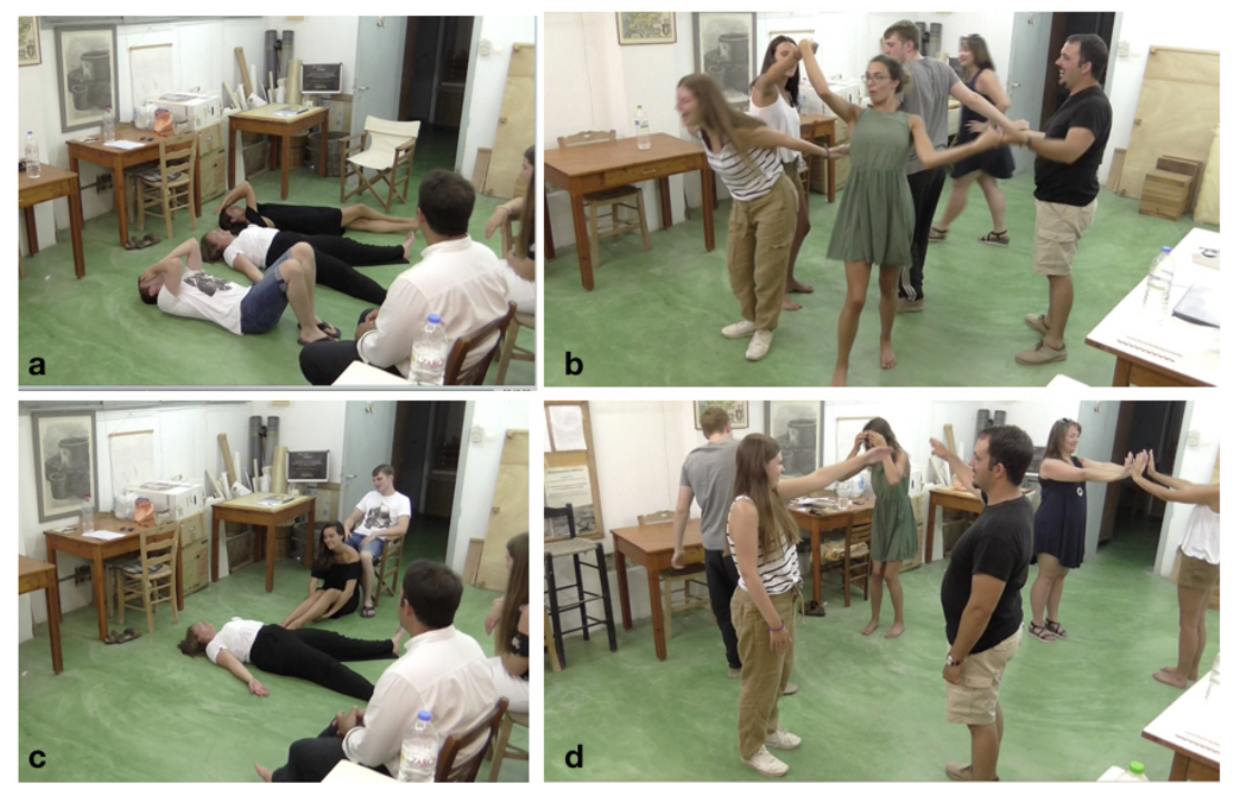

Figure 5: Snapshots from the Santorini workshops: a) and c) Who? Where? What?, b) Untangled, d) Mirror your peer

On the other hand, most of them considered as a weakness of the workshop the simplicity of some activities and they were also concerned that these activities might have been designed for a younger audience than themselves. In the final field, regarding any further thoughts they had, three out of the five participants thanked us for the unique experience they had and also expressed their further interest in combining drama and archaeology.

\section{Can we apply drama as a tool to better understand archaeological evidence?}

Even if the Santorini experiment on a performative method of exploring archaeological evidence is too small to offer definite answers, it was nevertheless a positive start. First, we realized that the idea of applying Process Drama as a methodological tool in archaeological practice is something that can offer tangible outcomes. Our sample was small, only five people from the same context, but one thing that stands out prominently in the participants' feedback is that drama workshops helped them to understand the archaeological evidence better. Students were able to engage with survey finds in many different ways, and excersises, like 'artefact on the wall' or 'two truths and a lie' allowed them to brainstorm collectively, exchange ideas, and come out with multiple interpretations. The 'Exploration' part , the core of our approach, was the exact part of the workshops were all these interpretations were cultivated. After the 
introductory drama games students were more confident to share with their collegues their perceptions and ideas on the material and to 'play' really with the recorded archaeological evidence. As an example, hand grinding stones that have been found in the caves were correlated with the possible caves' functions - caves as animal pens and/or caves for possible prehistoric occupation - and more lively explanations about their present have been proposed. In other words, instead of the usual presentation of 'two hand grinding stones have been recorded at the light zone area of Zoodochos Pigi 2 cave', students could engage the stones' presence in the light area with possible activities that taken place and they had the need of light - preparation of cereals into flour for example. Thus, drama seems to have worked complementary to the traditional archaeological methods and allowed the archaeologists to realize, experience and embody the roles that Santorini's caves might have had in the island's past.

Particularly discussing about 'two truths and a lie' exercise students were able to express their own truths and lies about the archaeology of Santorini caves. Archaeology is a discipline that 'truth' is very difficult - if not impossible - to be uncovered. This is due to the nature of the archaeological evidence which is usually fragmented and with parts lost in time. Having students (and more senior researchers) to express different interpretations through games like the aforementioned, allow them to think deeper and with the help of the group to come out with possible (tue) or not very possible (lie) suggestions, always based on the available research data.

We are positive that there are unlimited different scenarios available that a trained drama facilitator-archaeologist can 'mix and match' in order to adapt the method to given research contexts and we are not willing this paper to become an exhaustive list of possibilities. As E. Theou suggests, the participation of artists in archaeological research and excavation, through an embodied and multi-sensorial experience can help in the creation of archaeological narrations. Moreover, aligned with our suggestions, artists, with their presence, will enrich the archaeological team, offering new insights into the material (Theou, Performance- Archaeology n.d.). As Seitz notes (2016:304) "the Performative turn in social research represents a fundamental movement away form a universal methodological culture and towards methodological pluralism". This paper ultimately aimed to instigate a debate and to encourage archaeologists to experiment with applying Process Drama as a research tool in order to understand the past in a broader, embodied, way. In other words, as we are 'performing' with research, why can't we equally be 'researching' with performance?

Acknowledgments - The authors would like to thank the Community Engagement Small Grant Scheme of Cardiff University that provided the financial support for the first parts of this research, along with the Hellenic State Scholarship Foundation and the Greek Archaeological Committee of the United Kingdom who supported the authors' doctorate studies. Cardiff University Global Opportunities Fund and the Ghar Parau Foundation offered travel 
support to Cardiff University students. Authors are also grateful to the Society for the Promotion of Studies on Prehistoric Thera, to the Akrotiri excavations, and to Prof. Christos Doumas, Dr Tania Devetzi, Argyris Mavromatis, and Lefteris Zorzos for their unconditional support and hospitality during the time spent in Santorini.

\section{Bibliography}

Baldwin, Patrice \& Hendy, Lesley (1994): The Drama Book: An Active Approach to Learning. London: Collins Educational

Boal, Augusto (1995): The Rainbow of Desire: The Boal Method of Theatre and Therapy. New York: Routledge

Bolton, Gavin (1999): Acting in Classroom Drama: A Critical Analysis. USA: Calendar Islands Publishers

Borgdorff, Henk (2007): Den Modus den Wissenproduction in den kuenstlerischen Forschung. In: Gehm, Sabine; Husemann, Pirkko \& von Wilcke, Katharina (eds): Wissen in Bewegung. Perspektiven der künstlerischen und wissenschaftligen Forschung im Tanz. Bielefeld: transcript, 73-80

Borgdorff, Henk (2009): Die Debatte ueber Forschung und Kunst. In: Rey, Anton \& Schoebi, Stefan (eds.): subTexte 03. Kuenstlerische Forschung Positionen und Perspektive. Zurich: Institute for Performing Arts and Film, 23-51

Brennan, Ross (2008): Educational drama: A tool for promoting marketing learning? In: International Journal of Management Education 8/1, 1-9

Bowel, Patrice \& Heap, Brian (2013): Planning Process Drama: Enriching Teaching and Learning. Oxford and London: Routledge

Cervera, Felipe (2017): Naming the Cosmos Death: On performance, astronomy and Katie Peterson's the Dying Stars letter. In: Performance Research 22/4, 28-34.

Day, Christopher \& Norman, John (1983): Issues in educational drama. London: The Falmer Press

Doumas, Christos G. (1983): Thera : Pompeii of the ancient Aegean. Excavations at Akrotiri, 1967-79. London: Thames and Hudson, c1983.

Ehrenspeck, Yvonne (1998): Versprechungen des Aesthetischen - Die Entstehung eines modernen Bildungsprojekts. Opladen: Leske und Budrich Hamilakis, Yannis (2013): Archaeology and the Senses. Human Experience, Memory, and Affect. Cambridge: Cambridge University Press

Hodder, Ian (2005): Post-processual and interpretive archaeology. In: Colin, Renfrew \& Bahn, Paul (eds): Archaeology: The Key Concepts. London: Routledge, 207-211.

Kalogirou, Konstantina (2016): Step into Drama and Teach English affordably. A Case Study from Greece. In: Scenario X/1, 16-29. 
Kalogirou, Konstantina; Sarwar, Sian \& Trimmis, Prokopios Konstantinos (2016): "Let's meet the Red Lady of the Paviland": Delivering the Prehistoric Narratives in Museum Education. In: Drama Magazine 22/2, 9-15

Kalogirou, Konstantina; Beauchamp, Gary \& Whyte, Shona (2017): Vocabulary Acquisition via Drama: Welsh as a second language in the primary school setting. In: The Language Learning Journal, 1753-2167

Kalogirou, Konstantina (2018): Vocabulary Acquisition via Drama. Ph.D. Aristotle University of Thessaloniki

Lewis, William \& Tulk, Niki (2016): Editorial: Why Performance as Research? In: PARtake: The Journal of Performance as Research. 1/1, 1-7

Moyes, Holley (ed.) (2012): Sacred Darkness: A Global Perspective on the Ritual Use of Caves. Boulder: University Press of Colorado

Parker, Andrew \& Kosofsky Sedgwick, Eve (1995): Performativity and Performance. New York and London: Routledge

Pearson, Mike \& Shanks, Michael (2001): Theatre/Archaeology: Disciplinary Dialogues. New York: Routledge

Peggy, Phelan (1993): Unmarked: The Politics of Performance. New York and London: Routledge

Pettitt, Paul (2016): Darkness visible. Shadows, art, and the ritual experience of caves in Upper Palaeolithic Europe, In: Dowd, Marion \& Hensey, Robert (eds.): The Archaeology of Darkness. Oxford: Oxbow books

Ronen, Dov (2001): Managing cultural, ethnic and religious diversities on local state and international levels in Central Europe: the case of Slovakia. Management of Social Transformation: Discussion Paper 50. UNESCO. Paris: France

Schechner, Richard (1985): Between Theatre and Anthropology. Philadelphia. Pennsylvania University Press

Seitz, Hanne (2009): Temporaere Komplizenschaften. Künstlerische Intervention im sozialen Raum. In: Wolf, Maria; Rathmayr, Bernhard \& Peskoller, Helga (eds.): Konglomerationen. Produktion von Sicherheiten im Alltag. Bielefeld: transcript

Seitz, Hanne (2016): Performative Research. In: Even, Susanne \& Schewe, Manfred (eds.): Performative Teaching, Learning, Research. Berlin: Schibri-Verlag

Skeates, Robin (2015): Imagining the sensual cultures of prehistoric Malta. In: Gheorghiu, Dragos \& Bouissac, Paul (eds.): How Do We Imagine the Past? On Metaphorical Thought, Experientiality and Imagination in Archaeology. Cambridge Scholars Publishing, 111-120

Somers, John (1996): The nature of learning in drama in education: In: Somers, John (ed.): Drama and theatre in education: contemporary research. Canada: Campus Press

Takahasi, Ken (2016): Dogu-mime. In: Rogers, Kate; Valdez-Tullett, Joana; Mataix-Ferrándiz, Emilia; Chittock, Helen; Cox, Grant \& Gandolfi, Eleonora 
(eds.): Sightations exhibition booklet. Southampton University: Theory Archaeology Group

Tringham, Ruth (1991): Households with faces: the Challenge of gender in prehistoric architectural remains. In: Gero, Joan \& Conkey, Margaret (eds.): Engendering Archaeology: Women and Prehistory. Oxford: Blackwell

Troendle, Martin \& Warmers, Julia (eds.) (2011): Kunstforschung als aesthetische Wissenschaft. Beiträge zur transdisziplinären Hybridisierung von Wissenschaft und Kunst. Bielefeld: transcript

Turner, Victor (1988): The Anthropology of Performance. New York: PAJ Publications

Wagner, Betty Jane (1976): Dorothy Heathcote - Drama as a Learning Medium. Washington, DC: National Education Association 